\title{
Urdimbres de la crisis del capitalismo: proceso histórico y colapso civilizatorio
}

\section{Humberto Márquez Covarrubias*}

Resumen. El sistema capitalista mundial está compenetrado por diversas expresiones de la crisis. A escala superficial y coyuntural, el capitalismo global experimentó en años recientes el estallido del capital ficticio y el derrumbe de la arquitectura financiera que armonizaba la economía mundial. Fue necesario el rescate del Estado para solventar la bancarrota de las grandes corporaciones a costa de los contribuyentes y la mayor explotación de los trabajadores. En un estadio intermedio se resquebraja el modelo neoliberal y la forma de sobreproducción operada por las corporaciones multinacionales mediante la dislocación de la producción y el consumo en el mundo, la superexplotación de los trabajadores y la depredación ambiental a fin de concentrar capitales y apropiarse de los excedentes. Frente a la gran depresión se implementan severos programas de ajuste que depuran empresas, consolidan monopolios e imponen penurias a la población. En un nivel profundo, la crisis trastoca los cimientos culturales y políticos del entramado civilizatorio y cuestiona los fundamentos de la economía política, las fuentes de riqueza, es decir, la humanidad y la naturaleza; con ello el devenir de la humanidad y el entorno planetario se encuentran en predicamento.

Palabras clave: crisis, capitalismo, economía mundial, neoliberalismo, crisis civilizatoria.

* Docente investigador de la Unidad Académica de Estudios del Desarrollo de la Universidad Autónoma de Zacatecas, México. 


\section{Warps of the crisis of capitalism: historical process and civilizing collapse}

Abstract. The world capitalist system is visibly afflicted by various manifestations of the crisis. At a superficial and contextual scale, global capitalism in recent years experienced an upsurge in fictitious capital and the collapse of the financial architecture that facilitated the world economy. The State-led rescue of nearly-bankrupt large corporations to the detriment of taxpayers and even greater exploitation of workers was necessary. In an intermediate phase, the neoliberal model is divided and the mode of overproduction operated by multinational corporations through the dislocation of production and a ravaging of the world, the overexploitation of workers and environmental degradation, in pursuit of the goal of capital concentration and surplus expropriation. In the face of a massive slump, harsh adjustment programs were implemented that purged companies, consolidated monopolies and imposed hardships on the populace. To a very deep degree, the crisis disrupted the cultural and political foundations of the tapestry of civilization and questioned the fundamental concepts of the existing political economy, and sources of wealth - humanity and nature. As a result, humanity's future path and the entire world are placed in jeopardy.

Keywords: crisis, capitalism, world economy, neoliberalism, crisis of civilization. 


\section{Preámbulo}

Adentrada en un mundo donde además de supeditar las diversas formas de trabajo, la lógica del capital atrapa al consumo productivo e improductivo y al conjunto de actividades que involucran a la cultura, la política y la vida cotidiana. Los tiempos y movimientos que subyacen en la reproducción de la sociedad y la naturaleza son acompasados a una lógica normativa que sigue los imperativos de la valorización a escala mundial. En esa dinámica el signo de la crisis impregna todos los ámbitos de producción material y subjetiva de la modernidad capitalista y atenaza los mundos de vida.

La actual crisis del capitalismo mundial es compleja (entraña la acumulación de capital y la reproducción de la vida): enlaza esferas superpuestas del capital (producción, distribución y consumo), unifica horizontes temporales (corto, mediano y largo plazos), articula ámbitos espaciales (centros y periferias), entreteje clases sociales (capitalistas y trabajadores) y ensambla andamiajes políticos (Estados, instituciones, corporaciones, partidos, movimientos, sindicatos).

Conjuga dimensiones, ámbitos, temporalidades, intereses y agentes a través de las principales contradicciones del capitalismo para dar forma a una crisis de gran calado, una crisis sistémica que degenera en una crisis civilizatoria; es decir, un cortocircuito en el proceso de valorización dentro de la economía mundo cuyo trasfondo es la ruptura en el metabolismo social, en el sistema de reproducción de la vida humana y el entorno planetario.

La consideración analítica de esta problemática suele cargar la tinta sobre los grandes desafíos que acotan o ponen en jaque a la vida humana y 
natural; en contrasentido suele manifestarse incredulidad al expresar que es un problema pasajero, recurrente, del cual se saldrá bien librado. No es tanto un problema de percepción como de una acumulación de desajustes, desequilibrios, desproporcionalidades y contradicciones que tornan insustentable o inviable la vida socioambiental. La modernidad capitalista se encuentra en vilo toda vez que su estrategia de «globalización neoliberal» está socavando aceleradamente las fuentes de la riqueza social (humanidad y naturaleza) por lo cual está en predicamento la coexistencia de los sistemas de vida. Esta situación advierte desenlaces catastróficos que reclaman cambios económico-políticos sustanciales.

\section{Expansiones y fisuras}

La palabra crisis permea todas las capas de la sociedad, aflora en el lenguaje común y atiza el debate político. En primera instancia aparece como un quiebre en los centros neurálgicos del capital global, donde se asientan los poderes financiero, industrial y comercial, que han configurado la actual economía mundial. Es posible apreciar en lo inmediato la fractura de la rentabilidad de las grandes corporaciones multinacionales. Aparenta ser un problema coyuntural semejante a otras crisis económicas que con frecuencia atormentan al capitalismo tardío en distintos países, pero ahora el epicentro se localiza en Estados Unidos, nada menos que el hegemón, la principal fuerza gravitacional de la acumulación mundial. El capitalismo del nuevo milenio funciona como un gran molino de viento que agita dos poderosas aspas: la exorbitante acumulación de capital ficticio y el exceso de producción; se trata de fuerzas 
dinámicas que a la vez que impulsan la actividad económica destruyen los tejidos socioambientales.

\section{Ficticios estallidos genéricos}

Los despachos económicos se remiten a mediados de 2008, cuando en Estados Unidos, eje toral de la economía mundial, estalló una burbuja financiera por una miríada de aguijonazos propinados por una multiplicidad de insolventes deudores hipotecarios que inevitablemente cayeron en la morosidad de pagos. El capital ficticio se había solazado con una serie de instrumentos financieros derivados y titularizados que colocaba en la órbita financiera créditos de alto riesgo convertidos en mercancías ficticias y vendidos en oleadas sucesivas entre operadores especuladores de diverso signo. En la morfología del capital ficticio participaban distintos agentes — grandes bancos privados, fondos de inversión, bolsas de valores, aseguradoras, fondos de pensiones- que engullían los excedentes de capitales productivos, fondos públicos, deudas soberanas y ahorros.

Una arquitectura financiera tan endeble, que había bombeado ganancias espectaculares, pronto se colapsó y puso al desnudo, una vez más, el funcionamiento parasitario del capital ficticio. La afectación inicial sorprendió a los bancos estadounidenses, desde los pequeños y medianos que operan en los ámbitos local y nacional hasta los grandes bancos globales que tejen las redes de los circuitos financieros en el orbe. En esa plataforma financiera de gran alcance aconteció una suerte de efecto dominó que se desplazó con prontitud hacia los otros centros vitales de las finanzas especulativas, Europa y Japón. Luego se propagó al conjunto de la arquitectura económica mundial, cuyo sistema circulatorio estaba armonizado 
por el capital financiero y pasaba por momentos de esplendor al punto en que los análisis convencionales, y buena parte de los heterodoxos, se habían reducido al dominio de las finanzas.

Para ofrecer una explicación plausible de la crisis, el relato pergeñado por tecnócratas, académicos y comunicadores afectos a la economía de mercado sigue la trama de la desregulación, la especulación y la codicia de bancos y bolsas que operan los mecanismos de titularización de créditos con alta dosis de riesgo sin limitaciones, en la oscuridad y con impunidad garantizada. La tesis financista alcanzó popularidad pese a que sólo daba cuenta de la superficialidad de un episodio cargado de dramatismo que apenas representaba la punta de un iceberg. En el trasfondo se ocultaba un colosal entramado de operaciones amañadas y fraudulentas orquestadas por el gran capital financiero que actuaba de modo reticular y ficticio a escala internacional, sobrepasando los controles estatales y las fiscalizaciones de organismos internacionales, sin consideración alguna de los intereses de las clases populares y las múltiples afectaciones a los trabajadores.

Una especie de fascinación envolvía al mundo que se entregaba a la mercantilización, el consumismo y la espectacularidad de un capitalismo triunfalista, que incluso ya no se reconocía como tal al no tener un oponente de gran calado encarnado en un proyecto económico-político asequible, sino que se presentaba como la cristalización de la historia humana y la personificación del progreso. El predominio de las finanzas, el empuje de las tecnociencias y la proclamación de la democracia representativa hacían las veces de un destino manifiesto coagulado en la modernidad capitalista, el neoliberalismo y la subjetividad individualista. Pero el estallamiento de lo que genéricamente se designa como «financiarización» desmoronó la utopía capitalista del mercado total y puso a la luz del día, 
como si fuese una revelación, una novedad cristalina: el funcionamiento perverso del capital ficticio. Entonces, proliferaron informes que hacían un recuento de los daños en los diversos ámbitos de la vida social. Después de la orgía del capital especulativo, la epifanía de la cruda realidad significó un reencuentro tormentoso con el realismo salvaje. Prácticamente en todo el mundo los espectadores contemplamos una lección instantánea sobre el capitalismo (Katz, 2008), un vocablo que en gran medida había sido desterrado de la academia y la política.

En las últimas décadas, el dinero conducido por los circuitos financieros globales especulativos experimentó una bonanza de ganancias ficticias amparadas por una barroca formación de burbujas financieras insufladas por la titularización (securitización) que permitía a los enormes bancos desprenderse de numerosos créditos que en términos contables eran inviables, dudosos y riesgosos, pero que las instituciones bancarias transferían a otros agentes financieros en grandes caudales que paulatinamente fueron anegando los receptáculos de la economía mundial con una cantidad abrumadora de papeles preñados más que de liquidez de pura incertidumbre: bonos diversificados y seguros para títulos incobrables apalancan las obligaciones crediticias con el respaldo de poco capital propio y crédito riesgoso. Signo de los tiempos, las ganancias ficticias inconmensurables se fundamentan en instrumentos colmados de riesgos (Carcanholo y Sabadini, 2008).

Sin embargo, bajo la ética del capitalismo, cuyo principio central es la maximización de las ganancias sin importar los daños humanos y ambientales, la orgía especulativa era una muestra de vitalidad dentro de una economía mundial sin fronteras. En el teatro de operaciones, la especulación desbordada pretende hacer caso omiso de los daños colaterales — meras 
externalidades - e ignorar los riesgos crediticios; pero víctima de sus propios excesos, el entramado financiero recayó en un estado de hipertrofia que redundó en la inflación de una burbuja especulativa amplificada. La búsqueda afanosa de altos márgenes de rentabilidad financiera mediante el traspaso de los riesgos hacia agentes financieros colaterales se convierte en un mecanismo depurador de incertidumbres y en un estímulo mordaz para que los bancos incrementen la colocación de créditos, créditos y más créditos, sin reflexionar - el capital no acostumbra a recapacitar - en que el dinero así otorgado pueda ser en efecto recuperado, como dictaría la norma. Simplemente el riesgo se transmite y se genera una vasta red de operadores especulativos, convidados de la danza orgiástica de las ganancias ficticias, que por mucho tiempo han trazado el espíritu del capitalismo de entre siglos y punta de lanza del nuevo milenio.

El consenso de las elites financieras plasmado en la política neoliberal que alienta la desregulación para permitir la expansión sin cortapisas del capital financiero desbocado es el acicate de un caudal de prácticas disolutas que permiten la ejecución de masivas operaciones riesgosas y discrecionales. No obstante, todo parecería hallarse bajo el control de comedidas instancias supervisoras de la probidad del ambiente financiero y de la salubridad de los mercados. El desenfreno crediticio es convalidado por reputadas agencias calificadoras que presumen regular o definir los niveles de riesgo de tales mecanismos de propagación crediticia; al contrario, en vez de cumplir su atribución con responsabilidad, como dictaría la sacrosanta institucionalidad burguesa, terminaron por unirse al festín del gran dinero y a la postre fueron cómplices de la gran trama especulativa. El botín era demasiado apetitoso, de ahí que no se emitieran dictámenes precautorios y restrictivos. 
Los bancos, presentados como las instituciones más eficientes y armonizadoras de la sociabilidad económica de la modernidad tardía, no administraron el factor de riesgo con sobriedad y responsabilidad. En lugar de propiciar la regulación y autorregulación financieras, fueron consecuentes con la racionalidad irracional del capital que hace de la competencia el dínamo de la maximización de beneficios, y en tal sentido se entregaron a la frenética competencia interbancaria compelida por el «sano afán de lucro» mediante la multiplicación de créditos de alto riesgo y la consecuente propagación de papeles que se transferían a otros agentes participantes de la juerga de una economía escrita con argumentos ficticios. Los créditos tóxicos fueron la epidemia global más nociva de principios del siglo XXI, dejando a las muy publicitadas influenzas como enfermedades pueblerinas.

La fenomenología del capital ficticio cobra vida con el alto riesgo asumido, se alimenta de la efervescencia especulativa y redunda en la inflación de ganancias ficticias, que no tienen parangón en otros sectores económicos, pero el virus estaba inoculado y se decantó en la emergencia de una enfermedad perniciosa, una crisis de sobreacumulación en el ámbito financiero, hasta entonces el sector más dinámico de la economía mundial. El capital ficticio engendra la imagen horrísona del enriquecimiento desmedido y la convulsión económica en el planeta.

Esta crisis no es similar a otras registradas en las últimas dos décadas en países periféricos como México, Rusia, Brasil, Turquía, Argentina o el sudeste asiático. O la reciente crisis de la deuda pública en Grecia apuntalada por bonos derivados de Estados Unidos. Crisis que han estado latentes en España, Portugal, Italia, Argentina, México. Un rasgo novedoso es que el epicentro de la crisis no se ubicó en los eslabones débiles de las 
economías periféricas, sino que impactó en el centro del capitalismo mundial: Estados Unidos, que ha fungido como el hegemón, el gran imperio, desde la segunda posguerra hasta el presente. En virtud de que este centro de centros — con el acompañamiento de socios estratégicos como la Unión Europea, Japón y China- se conecta con el resto de regiones, bloques y periferias, cuyos conectores cardinales son las finanzas globales, los mecanismos de propagación actuaron con virulencia y la crisis financiera se esparció con prontitud hasta los confines del planeta, aunque de forma diferenciada, por lo mismo se puede observar que las regiones entregadas sin cortapisas a los dictados económicos imperiales son más vulnerables, pues han desmantelado todas las barreras defensivas y modos de gestión soberana de sus propias economías; en contraste con los proyectos de nación que intentan erigir diques y articular economías vinculadas con mecanismos de intercambio comercial menos perniciosos. Al respecto, los efectos dañinos afectaron y tomaron como correas de transmisión a Europa, donde los estragos fueron muy fuertes, y a Japón, donde también fueron muy perniciosos, para después extenderse por el planeta con un pesado efecto recesivo, que todavía sigue vigente en numerosas economías centrales y periféricas (Roberts, 2017).

Desde una mirada inmediatista, proveniente de los despachos informativos publicados en los medios de comunicación y de los artículos de análisis plegados a la situación de la coyuntura, se puede tomar nota que la crisis financiera comenzó a forjarse en 2007 y estalló en 2008. También puede agregarse que no se trató de una crisis cíclica, en el sentido de que siguiera un supuesto curso natural en el que las propias fuerzas del mercado fueran las que paulatinamente ayudaran a salir del escollo y transformaran la gran depresión en recuperación con miras a un ascendente 
empuje hacia un nuevo auge económico. Es bien sabido que el libre mercado entraña una falacia y que el Estado mínimo que postula el neoliberalismo es una quimera, pues sólo se reducen las funciones sociales estatales en la misma medida en que se refuerzan las políticas orientadas a la contumaz acumulación de capital.

En efecto, la debacle fue contenida, hasta cierto punto, por la necesaria y providencial intervención de los Estados. Apenas se estaba elaborando un diagnóstico mínimo de la crisis cuando al año siguiente los agentes del Estado hacían acto de presencia para rescatar al gran capital financiero e industrial que se desmoronaba en su propio pantanal mediante el infausto mecanismo de socialización de la deuda con fondos públicos, con cargo al contribuyente y a una explotación redoblada de los trabajadores. Al rescatar a los bancos con fondos públicos no se redime al capital ficticio, sino que se reaviva a Wall Street, centro financiero mundial, para que se entregue de nuevo a la francachela y se ponga de inmediato a fraguar nuevas burbujas especulativas en el sector financiero y en otros sectores productivos: materias primas, bienes raíz, monedas de mercados emergentes, etcétera.

Paradójicamente, el rescate financiero con fondos públicos posibilita la regeneración de condiciones económicas para inflar nuevas burbujas especulativas con el riesgo de más estallidos, como se advirtió en Dubái y Grecia, y estuvo a punto de acaecer en España, Portugal e Italia, además de los embates especulativos sufridos en Argentina y México. Claro está que los sectores populares, las clases trabajadoras y las instituciones de servicio público, damnificados en grado sumo por la crisis, no fueron rescatados; al contrario, se les pasó la factura. Se aplicaron programas más severos de flexibilización y precarización laboral, al igual que programas de despidos y se incrementaron las cargas impositivas a contribuyentes y consumidores 
en general, no así a las grandes corporaciones. Tales medidas contribuyeron a reforzar uno de los saldos de las crisis: reconcentrar los capitales, acumular las riquezas en pocas manos y golpear a las clases trabajadoras.

\section{Trasfondo productivo}

Más allá del microrrelato financista que sigue un guión predestinado que se trompica con el pleonasmo del dinero autorreferenciado y reduce el complejo mundo actual a la esfera del dinero ficticio y al atado de instituciones reguladoras y crediticias inmersas en una arquitectura financiera global apuntalada por instrumentos convencionales y derivados acompasados mediante formas de contabilidad no muy creativas, es evidente que el descalabro económico no sólo acontece en el mundo del dinero. El mundo es más ancho que las caderas de los grandes bancos y fondos financieros. La crisis no consiste en un asunto exclusivamente financiero y en consecuencia los responsables no sólo son los agentes del capital ficticio (bancos, bolsas de valores, aseguradores, fondos de inversión y fondos de pensiones). En realidad, bajo la punta del iceberg se esconde una voluminosa economía globalizada que engendra el valor con mecanismos parasitarios y rentistas, en convivencia con las formas encubiertas de superexplotación, precarización, despojo, extractivismo y violencia, donde la forma crisis es una hidra de múltiples cabezas. La crisis tiene un amplio trasfondo, habitualmente ignorado, ubicado en la médula del capitalismo: la producción global, justo donde se engendra el valor, la sustancia de la cual se alimenta la dinámica del capitalismo.

Organizada en el terreno productivo por las grandes corporaciones multinacionales y sus aliadas nacionales, la economía mundial ha 
desplegado una gran capacidad productiva merced a una extensa variedad de nuevas tecnologías y medios de transporte, el respaldo estratégico de los Estados y del capital financiero, que redunda en la sobreproducción, un severo problema estructural que ocasiona cortocircuitos en los procesos de valorización. En la afanosa búsqueda de ganancias extraordinarias, en el menor plazo posible y al más bajo costo permisible, los capitales compiten con todos los elementos a su alcance. De forma clásica introducen mejoras tecnológicas en la producción y convierten a la ciencia en una fuerza económica aplicada a la órbita de los negocios, pero en la era del capital global además se valen de la sobreabundancia de fuerza de trabajo barata, desorganizada y desechable, dispuesta a ser explotada, incluso superexplotada, para articular redes de fábricas diseminadas en Asia, América Latina y otras regiones, mediante formas productivas relocalizadas desde los grandes centros industriales de las economías centrales a las periféricas que toman la forma aparente de «fábricas globales» en los enclaves exportadores.

Dichos territorios son reservorios de recursos naturales, biodiversidad y formas culturales que se convierten en abastos de materias primas, fuentes de energía, productos básicos y saberes tradicionales engullidos por la maquinaria productiva a través del cercamiento de bienes comunes y el despojo de medios de vida que derivan en contaminación, destrucción y aniquilación del medio ambiente y de comunidades, al punto que la naturaleza y la población se tornan en meros insumos productivos. En los denominados talleres del moderno «trabajo esclavo» se produce un «enorme cúmulo de mercancías» que inunda el mercado mundial a grado tal que irrumpe el gravoso problema de la producción superlativa. La pauta de la producción capitalista es desbocada, ciega, compulsiva y furiosa; a su paso 
encuentra severos problemas de realización y el estallido de crisis enraizadas en la razón íntima del capital: la valorización del valor.

La sobreproducción es un problema estructural y recurrente del capitalismo; sin embargo en la era del capital global no se constriñe a un país o una región, sino que acontece en el ámbito planetario, toda vez que la forma valor se mundializa, por tanto, se trata de un fenómeno de nuevo tipo, debido a que ahora es el capital multinacional el que en gran medida organiza la producción, la distribución y el consumo en el tablero de la economía mundial. En esa trama se reconfigura la división internacional del trabajo y la biodiversidad para articular redes globales de capital monopolista, una de cuyas expresiones es la reinserción de las periferias a las pautas de acumulación mundial centralizada mediante la reedición de economías de enclave en los sectores alimentario, extractivo, industrial, comercial, turístico, de servicios, financiero e inclusive criminal. Es una economía de amplio espectro largamente tejida por el capital global.

Un rasgo importante del capitalismo mundial es la desvinculación entre oferta y demanda. Merced a la sobreproducción y a la apertura al comercio internacional, los tratados de libre comercio y la expansión de las redes globales de capital monopolista, se arroja al mercado una cantidad inconmensurable de mercancías que inevitablemente se quedarán sin ser compradas. La sobreproducción invocará el problema de la realización que toma la forma aparente de subconsumo.

Otra dislocación importante, inscrita en la entraña íntima de la mercancía, es la desconexión entre valor de uso y valor de cambio. Las mercancías que inundan el mercado son lanzadas para ser vendidas, independientemente de su utilidad, incluso ahora son menos útiles y duraderas («obsolescencia programada»), más irrelevantes y desechables. La primacía del valor 
de cambio incentiva una mercantilización desbocada, la depredación de la naturaleza y el predominio de las tecnociencias; en suma, el privilegio de la valorización sobre la reproducción social.

La sobreproducción global es más voluminosa que las registradas con anterioridad, como en el sureste asiático en 1997. El desbordante excedente de mercancías, a la par de la sobreacumulación financiera y el estallido de la burbuja especulativa, provocó una gran recesión en la economía mundial que en 2009 requirió un enorme gasto público para contrarrestar los efectos recesivos, pero las medidas resultaron insuficientes, pues continúan los periodos de caída o estancamiento de la producción, que de manera convencional y limitada se registran en alicaídos crecimientos del PIB, la restricción del crédito, la contracción del consumo y el declive de la inversión.

\section{Rescate estatal y factura social}

Salvar en última instancia a los grandes capitales en apuros es una de las funciones conferidas al Estado, quien también debe ser un gestor oportuno del capital al abrir mercados, dotar de infraestructura, controlar a los trabajadores, brindar un ambiente de seguridad a la inversión y otras actividades a fin de garantizar los márgenes de rentabilidad. No obstante, en épocas de crisis salen a relucir los programas de rescate financiados con fondos públicos, que abren enormes boquetes al erario, cuya huella se imprime en la figura duplicada de la deuda pública incrementada y la profundización del déficit fiscal. Entonces se desencadena una espiral de finanzas públicas debilitadas; para compensarlo, los gobiernos implementan drásticas políticas de ajuste, presentadas como responsables programas de 
austeridad, que afectan directamente a los trabajadores y a la sociedad en general, pues se restringe, primero que nada, el gasto en servicios públicos (educación, salud y alimentación), además de que constriñen salarios y prestaciones a la vez que aumentan los impuestos. Comienza un nuevo episodio de abrogación de conquistas sociales y laborales previamente alcanzadas por pretéritas luchas sociales y en general se asienta un denso clima de regresión social.

En 2010 se implementó la política de ajuste con el propósito de rescatar empresas y bancos mediante la deuda pública. La problemática escaló por el efecto combinado de la acumulación de la deuda pública y el déficit fiscal, con la paradoja de que los banqueros, en tanto personificaciones del capital financiero, se presentaron a su vez como los acreedores de la deuda pública, y en esa trama reclaman siempre un lugar privilegiado para acceder invariablemente al premio mayor, de ahí que reciban el apelativo de buitres que se alimentan de las catástrofes sociales. De hecho, los gobiernos reservan las partidas más atractivas de los presupuestos para priorizar el pago de deuda y postergan o reducen el gasto destinado a la promoción del desarrollo social. Tal es la tónica del «salvataje» estatal en tiempos de crisis; política que se aprovecha además para bajar los compromisos públicos y establecerlos como parámetros de largo plazo, más allá del horizonte tentativo que supone el periodo especial de una crisis.

Cabe aclarar que la política de ajuste sugerida por los organismos financieros internacionales no se aplica con la misma intensidad y temporalidad en los países centrales y en los periféricos. Es sintomático que en Estados Unidos, Japón y los principales países europeos no se hayan aplicado las políticas contraccionistas y antipopulares; pero sí en el sur de Europa, donde se incuba una suerte de mundo periférico dentro de las economías 
centrales. La primera prueba de fuego se registró en Grecia, nación en la que se impuso un plan de ajuste diseñado por la Troika, es decir, la Comisión Europea, el Banco Central Europeo y el Fondo Monetario Internacional (FMI). El ajuste se impuso en Grecia y amenazó a España, Portugal e Italia. Sin embargo, la medida no es del todo novedosa, se remite a los programas de ajuste aplicados con determinación autoritaria en América Latina: disminución de salarios, reducción del gasto social, despido de empleados públicos, aumento de la edad jubilatoria y privatización de servicios públicos (escuela y salud).

En un mundo convulsionado por la expansión del capital ficticio y el exceso de producción, con un derrotero inmerso en ciclos económicos erráticos tendientes al estancamiento, atizado por severas políticas de ajuste, el costo social más relevante de la crisis global es la combinación del desempleo generalizado y la profundización de la pobreza, fenómenos que repercuten indubitablemente en la degradación social: hambre, violencia y migración forzada. Este es un desempleo estructural y una pauperización abarcadora que inevitablemente repercutirán con efectos recesivos en el ciclo económico y disruptivos en la dinámica de reproducción social que amplifican y dan continuidad a la crisis general. De igual forma, el desempleo y la pobreza no son problemas exclusivos de las economías subdesarrolladas; en Estados Unidos, pese a los informes sobre la recuperación del crecimiento del PIB y el aviso de que la recesión habría quedado atrás, el desempleo y la pobreza conforman problemas persistentes que redundan en exclusión, violencia e inseguridad. 


\section{Dislocaciones abismales}

Paradójicamente, la economía mundial ha estado articulada por una separación entre la producción y el consumo. La estructura funcional ha separado los espacios con mayor capacidad de producción y de consumo masivo. En uno de los polos China se consolida como el principal centro de producción (dentro de la tónica de la sobreproducción) soportado con altos niveles de ahorro e inversión, pero con bajos niveles de consumo, superexplotación del trabajo y depredación de la naturaleza, es decir, en un solo país, en este caso colosal, se sintetizan los principales rasgos que otrora permitían distinguir el desarrollo y el subdesarrollo. Por otra parte, Estados Unidos funge como el centro de mayor consumo (en la pauta del sobreconsumo), pero con bajos niveles de ahorro e inversión, un capital industrial menguante y altos costos de producción internos. Entre ambos polos existen muchos matices ejemplificados por el papel que cumplen las distintas regiones en la trama de la acumulación mundial (Katz, 2011).

No es un arreglo orientado por las fuerzas ciegas del mercado, sino que atiende a acuerdos geoeconómicos multirregionales pactados por las potencias capitalistas. La división internacional de la producción y el consumo permite a Estados Unidos asegurar altos niveles de consumo acorde con su cultura del derroche y la ostentación hedonista por encima de las posibilidades de su economía, mediante el abastecimiento de cantidades ingentes de mercancías baratas producidas ya no en su espacio económico interno sino en las economías periféricas en condiciones de superexplotación del trabajo, depredación de recursos naturales y altos niveles de inversión de capital, sobre todo en China y en países que fungen como proveedores o se adhieren al esquema de producción subordinada, tal como 
ha ocurrido en América Latina con la formación de economías de enclave, desde el «extractivismo» hasta la «maquilización». En gran medida, la estructura de la economía mundial está soportada por la reinserción de China como polo productivo. En tanto, el desequilibrio entre producción y consumo permite que el capital multinacional extienda sus redes globales de capital monopolista en las economías periféricas proveedoras de trabajo barato y recursos naturales desregulados (Márquez y Delgado, 2011).

Por supuesto que la economía mundial no se limita al nexo entre Estados Unidos y China. Tras el arreglo bipolar subyace un mundo económico multipolar que vincula los términos de la producción y el consumo entre diversas regiones con disímiles grados de desarrollo y relaciones de complementariedad, dominación y dependencia, según sea el caso. Estados Unidos extiende conexiones asimétricas con casi todas las regiones, una relación múltiple que le resulta muy provechosa para extraer el excedente económico y financiar sus déficits fiscal y comercial (Varufakis, 2012) al hacer valer su supremacía militar, el poder del dólar, el influjo de los monopolios, la preponderancia de los organismos internacionales que controla tras bambalinas y la omnipresencia de sus industrias culturales. China también ha diversificado sus lazos comerciales con Asia, Europa, América Latina y África; de modo particular, en Asia ha consolidado su liderazgo. Dentro de la Unión Europea, Alemania, Gran Bretaña y Francia mantienen relaciones con el resto. En tanto que América Latina se inserta como proveedor especializado de materias primas y fuerza de trabajo barata de China, Estados Unidos y Europa, pero con bajos niveles de ahorro, inversión y consumo (Katz, 2011).

La economía mundial opera en dos pistas principales y articula relaciones de poder bipolares y multipolares. No obstante, este esquema 
genera de forma inevitable desequilibrios comerciales y financieros. En la relación bipolar, los agregados comerciales propician un desequilibrio: el déficit comercial de Estados Unidos es financiado a escala mundial y también los excedentes comerciales y el sobrefondo de capitales en China. Por lo anterior, Estados Unidos aprovecha su hegemonía mundial con la intención de orientar los desequilibrios a su favor y consolidar una sociedad de hiperconsumo que engendra una base social de legitimación entre las masas de consumidores internos y externos afectos al american way of life. A la postre, la economía estadounidense funciona como un poderoso factor de atracción de los excedentes generados en la economía mundo y de las migraciones laborales multinacionales de contingentes altamente calificados, pero también de masas laborales inermes dispuestas a ocuparse en puestos intensivos, inseguros y mal pagados.

\section{Tensiones de entresiglos}

El neoliberalismo, la configuración política del capitalismo de entresiglos, significa una contrarreforma que derroca el poder del proletariado y la institucionalidad laboral con objeto de concentrar el poder y la riqueza en la elite burguesa multinacional y la oligarquía nacional. Este proyecto de clase cumplió su doble cometido pero engendró sus propias contradicciones hasta caer en una enorme y profunda grieta. Una mirada menos inmediata, apostada en el mediano plazo y más atenta al modelo de desarrollo capitalista que opera desde los 1980, puede advertir que está en curso una crisis estructural del capitalismo neoliberal. Empero, no representa una prolongación automática de la crisis precedente de mediados de los 1970; 
la cual culminó a principios de la década siguiente cuando las clases dominantes lograron imponer el proyecto neoliberal, que toma la forma de un modelo de desarrollo capitalista de alcance global, en cuya operación se van incubando múltiples contradicciones (Harvey, 2014).

El modelo de desarrollo capitalista neoliberal difiere del capitalismo de posguerra, el cual fue articulado por el modelo de acumulación basado en la producción fordista y en el consumo masivo tutelado por el Estado de bienestar o el Estado desarrollista para la región latinoamericana. En cambio, el modelo neoliberal se sustenta en las privatizaciones, la desregulación, la apertura comercial y la desvalorización del trabajo. Un recetario de políticas sintetizado en la expresión del Consenso de Washington. Las peculiaridades económicas y políticas del modelo suscitaron una serie de desequilibrios estructurales que estalló en la crisis mencionada de 2007-2008. Más allá del corto plazo, la crisis global abarca el periodo neoliberal que va de los 1980 hasta el presente. De manera agregada, la crisis global entraña los problemas cercanos en materia financiera, productiva y comercial (2007-2008 a la actualidad); también incluye los problemas acumulados en las últimas tres décadas de neoliberalismo, que aluden a la derrota histórica del trabajo por el capital.

Entre las contradicciones del modelo neoliberal, en la esfera financiera destacan la sobreacumulación (que genera una escalada de titularización), los derivados y el apalancamiento; en la esfera productiva, el capital multinacional provoca episodios de sobreproducción; en el comercio, los desequilibrios entre producción y consumo originados por los centros torales de la economía mundial (China y Estados Unidos) y otras regiones que activan nuevas dinámicas de intercambio desigual. La globalización neoliberal se complementa con arreglos políticos, militares y culturales 
igualmente contradictorios. En las últimas tres décadas, las contradicciones ensambladas a las de los años recientes del capital global se refieren a las limitaciones en las esferas de la realización y la valorización.

\section{Callejón sin salida}

El modelo neoliberal propicia una limitación crucial en el ámbito de la realización que termina por entramparlo. Conforme logra el cometido de ampliar los márgenes de rentabilidad mediante la disminución de los salarios y el incremento del desempleo, desvaloriza la fuerza de trabajo para extraer más plusvalor. Los trabajadores y sus familias se empobrecen y reducen drásticamente su poder de compra. Un efecto indirecto no intencional del modelo es el estrechamiento de la demanda. La pauperización generalizada de la población oprime al mercado porque el abatimiento del consumo popular vulnera la realización de las mercancías.

Por una parte, el neoliberalismo estimula altos márgenes de rentabilidad a costa del empobrecimiento de la población y, por otra parte, que constriñe la demanda. Esta contradicción contiene diferencias según los grados de desarrollo económico. En las economías centrales se aplican mecanismos de compensación, aun a costa de eventuales estallidos financieros; mientras que en las periféricas se combina la superexplotación y la inclusión al consumo a través de la «servidumbre por deudas» lo cual desencadena profundas crisis humanitarias.

En los países centrales se implementan diversas estrategias para alentar la demanda. Las clases sociales con altos y medianos niveles de ingreso mantienen elevadas cotas de consumo, que incluyen la ostentación y el derroche; las clases con ingresos medios, compelidos por la euforia 
especulativa, realizan inversiones financieras y conforme obtienen rendimientos de sus títulos incrementan o no su consumo; por último, las clases sociales de medianos y bajos ingresos, las más afectadas por la creciente desigualdad social y la reducción de salarios —especialmente en Estados Unidos-, a fin de mantener sus patrones de consumo padecen un progresivo endeudamiento familiar. A nivel agregado, la deuda de las familias erige la demanda efectiva y permite el sostenimiento del consumo para alentar periodos expansivos artificiales. El problema es más severo en el Sur global (África, América Latina y partes de Asia), donde habita la mayoría de los pobres del planeta. En esas demarcaciones las personas más pobres tienen exiguos grados de consumo y presentan cuadros patológicos de hambre, desnutrición, enfermedad y mortandad. Los informes evidencian que alrededor de 2 mil millones de personas padecen desnutrición y una cifra cercana sobrepeso (IFPRI, 2015), datos de una malnutrición derivada de la «dieta neoliberal» (Otero, 2013).

\section{Convulsiones orgánicas}

El modelo neoliberal no sólo acarrea el problema de realización concerniente a la fractura de la demanda o la incapacidad gradual de vender las mercancías, sino que reproduce un inconveniente estructural del capitalismo que se ubica en el crucial proceso de valorización. Al respecto, la valorización es un rasgo estructural del capitalismo soslayado en el modelo neoliberal. En el largo plazo la competencia obliga a los capitalistas a mejorar los procesos productivos mediante la mecanización; ello repercute en el incremento de la composición orgánica de capital y en el consecuente declive de la tasa de ganancia (Marx, 1867). Conforme la economía 
se mecaniza y automatiza por la generalización de nuevas tecnologías, se forma una gran capacidad de producción que redunda en efectos estructurales no intencionales que afectan la cuota de ganancia, esto es, en la medida en que los procesos productivos se automatizan impelidos por la competencia se disminuye la proporción del trabajo vivo y con ello se cae el plusvalor que sustenta el beneficio de los capitalistas.

Este proceso acontece primordialmente en los países desarrollados cuando se incrementa la inversión, los procesos económicos se informatizan y en consecuencia se amplifica el desempleo. Entonces el desempleo no sólo es un saldo coyuntural, como sucede si una empresa cierra, sino que deviene en un problema estructural debido a la automatización de la producción que aumenta la proporción de maquinaria frente al uso de fuerza de trabajo. La máquina de hierro devora al trabajo vivo y la naturaleza.

En distintos periodos y con diversas intensidades, la tendencia a la caída de la cuota de ganancia ha sido compensada con disposiciones como el incremento de la tasa de explotación de los trabajadores, el abaratamiento de las materias primas y la depuración de capitales. Sin embargo, tales contratendencias tienen sus límites: los trabajadores pueden organizarse y resistir para mejorar salarios y prestaciones; las materias primas baratas se agotan (petróleo, minerales); los procesos extractivos se encarecen o aumentan los precios debido a las especulaciones (presas de burbujas especulativas); y la monopolización puede conducir a la hipertrofia y a la sobreproducción.

\section{Huida hacia adelante}

Dos posibles rutas de salida a la crisis del neoliberalismo se advierten en el mediano plazo. En primer lugar, y a tono con la huida hacia adelante que 
acostumbra el poder, se vislumbra un relanzamiento del proyecto neoliberal. De lograrse, no sería esta la primera oportunidad en que pretenda superarse una crisis con estrategias más agresivas. Entre mediados de los 1980 y comienzos de 2000, las crisis fueron superadas implementando contraofensivas cada vez más devastadoras. En esta ocasión, se fraguó un resurgimiento vía la expansión de la demanda no sólo en los países centrales sino considerando un mundo multipolar que incluye a las economías emergentes (China, India, Brasil) que adoptan modelos neodesarrollistas para compensar, no contrarrestar, la caída del consumo en los países desarrollados.

La segunda ruta significa restaurar la tasa de ganancia, que se ha precipitado con la crisis actual, mediante la imposición de nuevas formas de explotación y la sustracción de excedentes de economías tributarias, como lo atestigua el programa de ajuste en Grecia y el relanzamiento de programas de privatización y flexibilización laboral. Estas medidas podrían aliviar los problemas estructurales de la crisis, pese a que pervivieran algunos de sus rasgos coyunturales.

Una dificultad mayor es la convergencia de las dos crisis, la global y la neoliberal. La unción de ambos componentes no sería una réplica de crisis neoliberales previas, sino que implicaría la crisis última del modelo neoliberal y estaría latente la implantación de otro modelo de desarrollo. Asimismo, cabe la posibilidad de una profundización del neoliberalismo con métodos más severos y mayor sufrimiento de la población. 


\section{Estertores civilizatorios}

El capitalismo despliega fuerzas productivas que fomentan esperanzas de progreso y desarrollo, al tiempo que desencadenan fuerzas contraproductivas y autodestructivas que socavan el funcionamiento del sistema capitalista (la valorización del valor) y acotan o amenazan al sistema de reproducción de la vida humana; por ende, a la crisis sistémica del capitalismo se suma el colapso civilizatorio (Márquez, 2010).

En la trama histórica del capitalismo, desde sus orígenes y durante su desarrollo, el sistema ha basado su reproducción en métodos violentos y rapaces que han arrasado civilizaciones y exterminado pueblos. De hecho el capitalismo emergió con la acumulación originaria (Marx, 2004). En el continente americano el arribo del capitalismo significó una colosal masacre de los pueblos originarios mediante la conquista y el régimen colonial. La modernidad capitalista solventó en gran parte su desarrollo industrial con el saqueo de las colonias y esta empresa transatlántica fue posible gracias a la esclavitud africana. Ya avanzado el siglo XX, el capitalismo renovó bríos tras dos guerras mundiales que redundaron en la emergencia de Estados Unidos como la indiscutible potencia mundial a costa de la muerte de millones de personas. En el siglo XXI persisten, se multiplican y convergen los mecanismos de saqueo, superexplotación y ecocidio.

En la trama histórica del capitalismo la crisis civilizatoria no es precisamente una novedad, pero en nuestro tiempo sí lo es el alcance y la profundidad que adquiere la crisis del capitalismo neoliberal, una grieta en el proyecto dominante de la modernidad capitalista, que adquiere visos de una fractura civilizatoria en la escena mundial que pone en entredicho las posibilidades de reproducción de la vida humana en vastas regiones del 
planeta merced a varias amenazas globales latentes que superan cualquier mal augurio o febril relato apocalíptico.

De manera acumulativa, según la secuencia del devenir histórico estructural, la crisis actual es una crisis del capital global, del modelo neoliberal y del modelo civilizatorio. Valga decir que es una crisis que entrelaza los problemas coyunturales, estructurales e históricos del capitalismo. Como producto histórico, el capitalismo presenta, en diversos momentos de su devenir, una contradicción que socava al sistema, más allá de los desajustes de las coyunturas. Se trata de una fuerza profunda que deteriora al sistema a largo plazo. Varios rostros de la crisis aparecen yuxtapuestos, algunos parecieran ofrecer perfiles más siniestros que otros, pero comparten como causa común la lógica del gran dinero sobrepuesta a la lógica de la vida humana digna.

\section{Desempleo estructural}

El fantasma del desempleo estructural que recorre la economía mundial es insuflado por dos fuerzas expansivas. La primera es la dinámica de expansión industrial que desde los 1970 del siglo pasado ha seguido una ruta paradójica de desindustrialización-reindustrialización. En las últimas tres décadas las empresas multinacionales con sede en Estados Unidos y las principales potencias capitalistas han perpetrado un traslado masivo de plantas industriales hacia los países periféricos — sobre todo a Asia y América Latina-, donde abunda el trabajo barato y existe una desregulación ambiental, aunado a que no tienen la obligación de cumplir leyes ambientales y laborales ni pagar altos costos por fuerza de trabajo y materias primas. 
En los países receptores se ha configurado un régimen laboral con condiciones miserables para los trabajadores y se ha generalizado la destrucción ambiental debido a la operación de industrias depredadoras. Estos espacios son verdaderos paraísos laborales y ambientales para saciar la sed de ganancia del capital multinacional. Las desmanteladas economías periféricas fueron previamente desindustrializadas con el propósito de insertarlas después a los sistemas productivos del capital global, por lo que se implementaron tratados y reformas legislativas para construir una tersa pista de aterrizaje del capital foráneo y el fácil despegue de los flujos exportadores. En esa trama, un caso paradigmático ha sido el Tratado de Libre Comercio de América del Norte (TLCAN), la punta de lanza para derrumbar los mecanismos de protección de la economía mexicana frente a los intereses capitalistas estadounidenses, derogar tasas impositivas, garantizar la seguridad de la inversión y facilitar los procedimientos para la explotación del trabajo y el medio ambiente, con lo cual se refuerza el bombeo sistemático del excedente generado de la periferia hacia el centro.

La otra fuerza impulsora proviene de los procesos de innovación tecnológica que han difundido cada vez más la automatización y la robotización de los procesos productivos, al igual que la adaptación de otras nuevas tecnologías. Al respecto, la Reserva Federal de Estados Unidos estima que se producen 85 por ciento más bienes con 2/3 partes de la fuerza laboral que se ocupaba hace veinte años (Ribeiro, 2017), sin considerar lo que se produce en el exterior. Las empresas más competitivas programan saltos tecnológicos que les permiten producir más con menos empleo. 


\section{Hambruna mundial}

Un problema coyuntural irrumpió en 2008 para escenificar la crisis alimentaria. En busca de nichos de ganancia extraordinaria y pronta, el capital financiero tomó por asalto de forma masiva al sensible sector alimentario. El centro operativo de la burbuja especulativa fue la bolsa de Chicago donde ocurrieron alzas artificiales de los precios de los granos (maíz, trigo, etcétera), de la soya y del etanol (producto del maíz o de la caña de azúcar); incrementos espectaculares que, en el caso del trigo llegaron a 100 por ciento en menos de un año. No fue la escasez sino la especulación lo que detonó el alza de precios. Según la Organización de las Naciones Unidas para la Alimentación y la Agricultura (FAO, por sus siglas en inglés), cayeron en la pobreza, en situación de hambre, 115 millones de personas. De aquí se deriva un problema ético: para el capital especulativo global el dinero es lo único que importa, en modo alguno los seres humanos.

La crisis alimentaria también ostenta rasgos estructurales. Durante el modelo neoliberal, en los últimos treinta años, está en curso un proceso de reconcentración de las tierras (conocido como acaparamiento de tierras) que significa una verdadera contrarreforma agraria a escala mundial. En términos gruesos, este proceso ha favorecido a las empresas multinacionales y a latifundistas locales. El hecho es que la agricultura, que había sido omitida por el gran dinero, de pronto se transformó en una nueva frontera para el capital. Es sabido que la agricultura campesina contribuye poco a la acumulación capitalista, pero se halla bajo su dominio (Bartra, 2006). Sólo su plena conversión en agricultura capitalista puede crear enormes rentas. Para ello es necesario incrementar notablemente la productividad (que en 
términos capitalistas puede alcanzar desde 100 hasta mil por ciento), pero con un considerable costo humano y ambiental.

En cualquier caso, la lógica inmarcesible del capital ignora las llamadas externalidades, saldos que no entran en los cálculos mercantiles. Los costos ecológicos y sociales no los paga el capital, los asumen las poblaciones afectadas. A mediano y largo plazos, el costo ecológico de la agricultura capitalista resulta desproporcionado. El uso masivo e intensivo de productos químicos que requiere la agricultura capitalista altera los suelos y contamina las aguas. Dicha producción reporta altos rendimientos en el presente, aunque previsiblemente configura las zonas desérticas del futuro. Las consecuencias sociales no son menores: la expulsión de millones de campesinos de sus tierras a barrios marginales de las grandes ciudades, lo que acentúa la crisis urbana.

\section{Migraciones forzadas}

La migración forzada es consustancial al capitalismo neoliberal. Las reformas neoliberales aceleran el proceso de acumulación por despojo que separa a amplios sectores sociales de medios de producción y subsistencia y los obliga a trasladarse a otras latitudes, del interior o el extranjero, en circunstancias que vulneran sus condiciones de vida y los colocan en la perspectiva de emplearse en situaciones de elevada explotación laboral y exclusión social. Los derechos humanos son conculcados en el origen, tránsito y destino. Las condiciones materiales de esta migración tienen como detonadores sintomáticos al desempleo estructural, la pobreza, la violencia, los conflictos, la inseguridad, las catástrofes naturales, al igual que la falta de oportunidades para el ejercicio pleno de las capacidades 
profesionales, intelectuales y artísticas, como sucede en el caso de la migración calificada.

No obstante, las causas profundas se localizan en las dinámicas del desarrollo desigual y el proceso de neoliberalización implementados con la intención de satisfacer las necesidades de acumulación de capital centralizado. La migración forzada responde a una estrategia de supeditación del trabajo inmediato y el trabajo conceptual (científico-tecnológico) en el horizonte transnacional. Las condiciones materiales repercuten en la configuración de una subjetividad adocenada que concibe a la migración como una cultura, una tradición y una estrategia de desarrollo, pero también como una expresión de malestar, resentimiento y rebelión ante las condiciones estructurales y políticas subyacentes en las causas profundas de la migración.

Al tiempo que el desmantelamiento del aparato productivo de las economías de las periferias se tradujo en la bancarrota de sectores clave para la subsistencia social — como el agrícola, en particular el modo de vida campesino-, fluyeron oleadas masivas de trabajadores migratorios que se vieron forzados a buscar el sustento en centros urbanos o campos de cultivo de sus países y en mayor medida en Estados Unidos y la Unión Europea, las zonas de mayor atracción de inmigrantes, aunque de igual forma se registraron grandes movimientos migratorios laborales al interior de los países, como ha ocurrido en China, por mencionar el caso más relevante. De ese modo, los principales centros económicos absorbieron grandes contingentes de trabajadores ya formados y dispuestos a emplearse en las peores condiciones laborales imaginadas. 


\section{Colapso energético}

Después de la Segunda Guerra Mundial, el uso de la energía fósil se incrementó, pero con el despliegue del modelo neoliberal el consumo aumentó de manera significativa y generó conflictos socioambientales. La acumulación mundial fosilizada, sustentada en el consumo de energía fósil a bajo precio, degeneró en el despilfarro, hasta prácticamente agotar las fuentes de petróleo barato o los yacimientos de diversos minerales. Los expertos anticipan que en el medio siglo venidero la humanidad tendrá que cambiar las fuentes de energía y modificar los patrones de consumo.

Paradójicamente, el gran dinero asume las crisis como ventanas de oportunidad para emprender nuevos negocios. Mientras que para amplios sectores poblacionales la crisis energética es grave, los capitalistas aprovechan los problemas que ellos mismos provocan con la finalidad de reconvertirlos en fuentes de lucro. Un ejemplo es la industria de los desechos, que se presenta como una vía de reciclaje, a la vez que continúan los vertederos de sustancias tóxicas y se agudizan los problemas de contaminación transgeneracional. Otro ejemplo es el surgimiento del negocio de los agrocarburantes tras la crisis energética, que a su vez propició el alza en el precio de los alimentos básicos. La tentativa de producir energía «verde» posterga la crisis y legitima el capitalismo al presentarse como si fuese consciente del cuidado y preservación del medio ambiente. La adopción del modelo de monocultivos de maíz o caña de azúcar para la producción de etanol o de palma, soya o jatrofa para la generación de agrodiesel propicia considerables daños ecológicos y sociales. La escasez de productos minerales y energéticos se acompaña de una escalada de las actividades militares, pues lo que se encuentra en juego es el control de las fuentes de energía y materias 
primas mediante el incremento desmesurado de la carrera armamentista y el asentamiento de bases militares en zonas geoestratégicas.

\section{Señales de ecocidio}

La crisis ambiental es uno de los sellos más conspicuos de la crisis civilizatoria. Algunos de sus rasgos son: cambio climático, calentamiento global; emisión de gases que supera la capacidad de absorción planetaria; profundización de la huella ecológica; aumento de sequías, tsunamis, inundaciones, extinción de especies; deshielo de glaciares e incremento del nivel del agua en las costas. No obstante, la crisis ambiental no puede atribuirse en abstracto a la actividad antropocéntrica y en tal sentido responsabilizar al hombre o la humanidad en general, o incluso adjudicarlo a la actividad de la naturaleza, como si fuesen simples catástrofes ambientales. No podemos omitir que en gran medida el sistema capitalista, que opera impelido por la competencia ciega en pos del lucro, ignora los límites de la naturaleza y continuamente los vulnera, lo cual deriva en la irracional sobreproducción de mercancías y, en consecuencia, en la devastación de la naturaleza que funciona como fuente perpetua de materiales y energía que nutren la producción capitalista.

En todo caso, se trata de una crisis histórica de degradación ambiental que no se reconoce y tampoco se atribuye la responsabilidad que tienen sobre ella los grandes capitales y las potencias económicas; en contraste, se asumen los costos financieros y rescates de bancos e industrias con esquemas que extienden el cobro de la factura a trabajadores y contribuyentes, mientras tanto se sigue reproduciendo el ecocidio. Por su parte, Estados Unidos bloquea los acuerdos mundiales y elude la reconversión energética 
para proteger sus industrias, de ahí que sea previsible la profundización de la degradación ambiental, quizá hasta un punto donde una mayor catástrofe afecte los grandes centros urbanos del mundo desarrollado, en grados más agresivos que, por ejemplo, los registrados por el huracán Katrina (Klein, 2007). Esta crisis no se resuelve con medidas simplistas como el impuesto al petróleo o al carbón, ni se advierte un milagro tecnológico de sustitución nuclear o del hierro del carbón. El mercado de emisiones, el negocio de conservación y todos los proyectos del capitalismo verde sólo auguran mayores desigualdades sociales y desequilibrios regionales.

\section{Conclusiones}

\section{La gran crisis del capitalismo global entraña} la convergencia de varias formas de crisis

La gran depresión de la economía mundial orquestada por los grandes capitales multinacionales, la contravención de la rentabilidad diseñada por el modelo neoliberal y la fractura del metabolismo social confluyen en una ampulosa crisis que atenta contra los fundamentos del sistema capitalista y contra la reproducción de la vida humana. Tal crisis gravita en los cimientos del sistema mundial y opera en distintos marcos temporales superpuestos que permiten dilucidar diversos factores explicativos, que al final de cuentas se funden en la lógica perversa del funcionamiento del sistema capitalista como un todo. Las crisis tienen compartimentos y vasos comunicantes: en un plano inmediato resalta la faceta coyuntural de la globalidad, en un nivel intermedio se ubica la estructura del modelo de desarrollo vigente (el neoliberal) y en las raíces se sitúa el sustrato histórico, 
el de mayor alcance, el componente civilizatorio que sintetiza la sustancia de la vida humana en el planeta.

\section{Deliberación sobre el diagnóstico y las soluciones} de las crisis en un ámbito de disputa teórica y política

Las concepciones teóricas y políticas sobre el desarrollo han sido afectadas por las crisis. Muchos partidos políticos, sindicatos y movimientos sociales, además de académicos y activistas que pretenden mejorar la situación están limitados porque permanecen en los marcos categoriales y políticos del modelo de desarrollo dominante y consideran que es suficiente implementar reformas en el sistema, como la regulación, sin advertir que la vida humana en el planeta se encuentra seriamente amenazada. Para impulsar un nuevo paradigma civilizatorio es preciso cambiar en principio las concepciones teóricas y políticas que emanan del sistema ideológico hegemónico.

La descripción, el análisis y la interpretación de la gran crisis se llevan a cabo en el ámbito de la disputa teórica. Es importante reconstruir el estado del arte, recapitular los debates relativos a las crisis, para analizar teórica y políticamente el trabajo de los investigadores y hacer investigaciones críticas de relevancia social; también es fundamental atender a las fuerzas sociales que actúan sobre las crisis en varios sentidos y con distintos intereses. La cuestión del desarrollo aflora como un campo en disputa, sujeta a debate, donde confluyen ideas, conceptos, explicaciones y propuestas desde visiones viejas, renovadas y novedosas. Evidentemente, no existe un consenso porque hay muchos intereses en juego.

Las visiones neoliberales amasadas en el Consenso y el Posconsenso de Washington, así como en sus variantes y adaptaciones, refrendan en 
especial los intereses del gran capital, pero el núcleo duro de esta expresión lo hace de un modo contradictorio: reclaman el rescate estatal de las grandes corporaciones con fondos públicos, cuando en el discurso ideológico abominan la injerencia del Estado, y preparan una contraofensiva que puede profundizar aún más la crisis porque siguen empeñados en ahondar las fuentes de ganancia extraordinaria mediante determinadas estrategias, que en cierto sentido pudieran catalogarse como «espurias»: superexplotación, especulación y extractivismo bajo una racionalidad irracional que pretende «estirar la cuerda hasta que se rompa».

La crisis desvirtuó el pensamiento único centrado en las premisas neoclásicas y el ideario neoliberal; entonces cobró cierto auge el pensamiento heterodoxo, sobre todo las posturas keynesianas que apuestan por una especie de humanización del capitalismo. Frente a la crisis, autores reputados como Stiglitz (2010) y Krugman (2012) postulan la idea de que para salir del pantano hay que reformar al Fondo Monetario Internacional (FMI) y someter al capital financiero mediante la rehabilitación de mecanismos de regulación; aunque es sabido que el capitalismo admite las regulaciones para procesarlas a su favor y llegado el momento conjugar los mecanismos de monopolización y control que le permitan obtener ganancias superlativas. La tentativa heterodoxa de humanizar el capitalismo a través de políticas de regulación y control con el propósito de contener la codicia y voracidad del capital se contradice en sus propios términos, puesto que el capital no reconoce límites, excepto los que eventualmente le imponen las crisis y la competencia.

El pensamiento crítico también se ha regenerado. En concreto el que impugna la explotación del hombre por el hombre y postula el principio de la emancipación humana. Ante los desafíos del colapso civilizatorio 
significa un proyecto histórico en beneficio de otro paradigma civilizatorio enfocado en la reproducción de la vida humana y no en los intereses del capital. Esta premisa no es posible dentro del capitalismo como sistema dominante. Garantizar las condiciones materiales y espirituales de existencia de la población es un asunto de la mayor importancia que no puede ser gestionado por el capital ni por burocracias fetichizadas en las altas esferas del poder sino desde instituciones democráticas en distintos niveles de la sociedad. Frente a la existencia de una crisis global, una conspicua crisis del sistema capitalista, la solución es un proyecto emancipador de la humanidad, un proyecto de largo aliento que carece de instructivos o de un solo camino; en todo caso se trata de un proceso en ciernes.

\section{Se libra una lucha de clases de largo aliento} con los dados cargados a favor del gran capital

Las crisis capitalistas, en su mayoría de raigambre económica, se resuelven en términos políticos. No existe un desenlace automático, una salida puramente económica, en el sentido simulado por los economistas: un ciclo económico que por sí mismo sigue una ruta de subidas, bajadas y nuevas subidas, como si las fuerzas del mercado fuesen racionales y recapacitaran. La historia lo demuestra: la depresión de los 1930 fue disipada con la guerra, que al efecto fuera caracterizada, y retomando las palabras de Karl von Clausewitz, como la «continuación de la política por otros medios», es decir, por las dos guerras mundiales —así llamadas pese a que se desarrollaron en territorio europeo con un destacado protagonismo estadounidense, a la sazón la potencia triunfante-; sin embargo, el boom de la posguerra se agotó con la oleada revolucionaria de los 1970; el neoliberalismo fue impuesto luego de 
que se asestaron relevantes derrotas a la clase obrera, y la etapa actual puede ser culminada por una acción política de las clases dominantes, aunque sin descartar los contramovimientos de los sectores oprimidos.

En la actualidad las respuestas que la crisis ha suscitado desde el Estado y el capital, pero también desde gran parte de los partidos, los sindicatos y los movimientos sociales, se refieren sobre todo a la capa inmediata o coyuntural de la crisis; a lo sumo se toma en cuenta el rescate o abrogación del modelo neoliberal, aunque se omite el componente sistémico, el funcionamiento del capitalismo, y también se desdeña el complejo entramado de la crisis civilizatoria, que va más allá del propio capitalismo. Con visiones cortoplacistas discurre un debate teórico-político en torno a diagnósticos, problemas, políticas y alternativas.

En el terreno de la lucha de clases, los proyectos de las clases dominantes frente a la crisis global tienen ventaja una vez más. El proyecto neoliberal se presenta como si fuese ahistórico, y más aún como si el capitalismo fuese eterno, una suerte de estado natural de la humanidad, y en tal sentido estuviese dotado de una capacidad de reproducción infinita, por lo que sus defensores esperan que siempre tenga la capacidad de renacer a partir de la recuperación del campo económico. No en balde se manifiesta como el mejor de los mundos posibles. Esta mitología ha sido desacreditada en los ámbitos políticos e ideológicos por la crisis general. En consecuencia, se puede afirmar que «la moneda está en el aire»; sin embargo, de acuerdo con Warrent Buffet, el tercer hombre más rico del orbe, «hay una guerra de clases, pero es la mía, la de los ricos, la que está haciendo esa guerra, y vamos ganando» (Stein, 26 de noviembre de 2006).

Desde el frente popular, la crisis de la civilización actual exige una revisión detallada del estado del mundo, que entraña múltiples aplicaciones 
a realidades concretas. Empero, se advierte que la acción de las clases populares no ha sido lo suficientemente fuerte, organizada y perdurable a escala mundial. El capital actúa a nivel global, no así los trabajadores; tampoco las instancias de representación popular. Las reivindicaciones de los movimientos sociales en el mundo lo testifican. En general, los movimientos representan fracciones del sector popular: campesinos, indígenas, obreros, mujeres, jóvenes, etcétera. No es suficiente expresar alegorías a la «multitud» o la «primavera de los pueblos» para congratularse de la emergencia de fuerzas transformadoras efectivas. Es imprescindible articular una perspectiva holística en la teoría y la práctica para develar la ubicación de cada cual en el conjunto.

Pese al descrédito del capitalismo y su proyecto neoliberal, la correlación de fuerza en el mundo sigue siendo favorable al capital. De hecho, la debilidad popular permitió al capital global salir bien librado en 2009 con los múltiples programas de rescate de corporaciones financieras e industriales sumidas en la bancarrota con cargo a los contribuyentes y no a un fondo de capitales. Además la derrota del movimiento obrero posibilitó una mayor extracción del valor de los salarios mediante la aplicación de severos programas de ajuste que contribuyeron a recuperar la riqueza de la plutocracia y a deteriorar la calidad de vida de la mayoría de la población.

El caso de Grecia en 2010 fue revelador: el capital financiero enfrentó y venció a un pueblo entero y lo sometió a un severo plan de choque llamado «austeridad» (Badiou et al., 2013). La finalidad era garantizar el cobro de obligaciones por el capital financiero internacional en detrimento de la calidad de vida de la población y del desmantelamiento del Estado y la democracia como instancias de representación popular. Claramente, no sólo fue una derrota implacable del pueblo griego, sino una derrota 
ejemplar de los pueblos del mundo que ven desvanecer las aspiraciones de soberanía popular ante los poderes imperiales y se encuentran una vez más enfrentados a los castigos que significan los programas de ajuste. Al final de cuentas, los programas económicos refrendan poderosos intereses de clase que se dirimen en la arena política mediante discursos teóricos y políticos que salen triunfantes en la medida en que están respaldados por correlaciones de fuerzas favorables.

\section{América Latina se ha configurado como laboratorio de transformación social merced a movilizaciones sociales y formaciones políticas posneoliberales y anticapitalistas}

En América Latina están en curso diversos procesos de transformación social sujetos a extensas deliberaciones y al acoso de los poderes imperiales y oligárquicos. No sólo se discute y vislumbra en esta región del mundo el proyecto de cambio social acorde a los pueblos latinoamericanos sino que también, de diversas formas, se forja el futuro de la humanidad o al menos se presagian otros horizontes con la certeza de que el futuro posible y necesario de una humanidad digna y provechosa es irrealizable bajo la potestad de un puñado de capitalistas.

Las experiencias de los zapatistas en México; los campesinos sin tierra en Brasil; la movilización de los pueblos originarios en la región andina, amazónica y maya; los gobiernos populares en Venezuela, Bolivia y Ecuador, en distintos planos y niveles, con mayor o menor intensidad e impetus transformadores; han acuñado o reivindicado conceptos y experiencias por demás útiles para la reflexión y la proyección política: «mandar obedeciendo», Sumak Kawsay, Buen Vivir, socialismo del siglo XXI o 
socialismo comunitario. En términos generales, anteponen las necesidades radicales de la población a los intereses radicales del capital y plantean relaciones sociales democráticas y comunitarias, otra forma de organizar la economía y un nuevo vínculo entre el ser humano y la naturaleza.

Esos conceptos son poderosos en tanto atribuyen al capitalismo y sus valores una condición histórica y perecedera, no un estado permanente y definitivo de la humanidad. No se trata de un retorno al pasado, sino una construcción del presente y futuro de la humanidad. Además, son críticos porque representan lo contrario de los valores del sistema capitalista y son propositivos de nuevas formas de organización de la vida colectiva de la humanidad en el planeta. Tampoco consiste en la implantación de otros dogmas de fe ni cosmovisiones específicas que tengan que ser reimplantadas en los contextos más heterogéneos. Más bien son caminos, modos de pensar y actuar sobre la realidad para transformarla.

Las aportaciones de los pueblos indígenas, las comunidades campesinas, los movimientos sociales, los sindicatos, los partidos políticos, los investigadores y los intelectuales afines a estos proyectos políticos ofrecen múltiples ideas y propuestas para solucionar una crisis civilizatoria que no es localizada, sectorial o privativa, sino que es universal e interpela al conjunto de la humanidad, por lo que su tratamiento reclama una pluralidad cultural y política, un trabajo colectivo de clases, movimientos y comunidades.

El horizonte de posibilidades de un desarrollo humano orientado por el sentido de la vida es de talante poscapitalista

En un sentido profundo, la crisis del sistema capitalista sólo puede superarse trascendiendo al sistema mismo (Amin, 2009). La tentativa de 
reformar el sistema mediante la regulación (Stiglitz, 2010; Krugman, 2012) o la decencia o humanización del capitalismo (Sen, 2009; PNUD, 2014) es poco menos que ilusoria, pues es bien sabido que el sistema se funda en la explotación, una relación social que de suyo no puede ser humanizada. De igual manera, la defensa de los derechos humanos como un dispositivo político del propio sistema no busca seriamente la emancipación social, a lo sumo pretende reparar ciertos agravios, resarcir a determinadas víctimas, atemperar algunos abusos de autoridades, pero no desatar el nudo crítico de la explotación y la dominación que seguirá generando víctimas bajo la forma aparente de la violencia, la exclusión y la pobreza. Otro tanto puede decirse de la democracia representativa, que simula la participación popular en la toma de decisiones, cuando se trata de un simulacro de las elites que detentan el poder político.

Resulta evidente que un sistema dirigido hacia la búsqueda insaciable de ganancias no repara en el respeto de la persona y si lo enuncia es con fines de maquillar, colocar una careta de rostro humano, a un sistema inhumano. Al basarse en la competencia y a la vez en el monopolio es incapaz de procrear una cultura de solidaridad. Tal pretensión constituye una utopía irrealizable, una mera ideología. En el largo plazo, el único proyecto sustentable para la humanidad es una sociedad poscapitalista, que todavía carece de nombre al ser un proyecto en construcción, con avances y contradicciones, pero que ya comienza a tomar forma en prácticas instituyentes, municipios autónomos, gobiernos populares, constituciones libertarias... 


\section{La defensa de la humanidad y la naturaleza amerita un nuevo paradigma civilizatorio}

El sistema capitalista ha producido el mayor cúmulo de riqueza en la historia de la humanidad, pero también ha desbocado una enorme capacidad destructiva que relega sus atributos constructivos. Esta contradicción no se reduce al ámbito material de las relaciones sociales, donde se dirimen las formas de explotación y dominación; además es una cuestión ética en tanto se plantea la disyuntiva de la primacía de los intereses de la reproducción del capital o de la reproducción de la vida humana (Dussel, 2013). Asimismo, es una encrucijada civilizatoria que pone en entredicho el desarrollo capitalista explotador y excluyente con la finalidad de replantear otro paradigma de desarrollo humano.

No sólo está en cuestión la perversión con la que opera la estructura del capital global, que para satisfacer su sed de ganancia recurre a la superexplotación del trabajo, la especulación financiera y el extractivismo de bienes naturales, ni los mecanismos de distribución del excedente en forma de plusvalor y renta, también se encuentra en peligro la pervivencia en el planeta de la vida humana, inmersa en una naturaleza depredada. El problema es tan serio que no puede ser resuelto únicamente por economistas, tecnócratas, especialistas y la clase política, sino que interpela a la humanidad, a todas las esferas del pensamiento y de la praxis social, pero de manera particular a los sectores subalternos que llevan la carga del trabajo y las penurias de la sobrevivencia. No sólo se delibera sobre la posible extinción del capitalismo sino del futuro de la humanidad.

Más allá del capitalismo, depredador de todo lo vivo y aun de lo muerto (el trabajo vivo y el trabajo muerto, la materia biótica y la materia pétrea, 
los recursos renovables y los no renovables, lo animado y lo inanimado), es imprescindible formular otro paradigma civilizatorio y replantear los fundamentos de la vida humana en la Tierra. Ante la primacía del valor de cambio que funge de catalizador de las relaciones sociales en las que la mercancía es un fetiche, se antepone la necesidad de privilegiar el valor de uso como soporte de la producción material de la vida. La consideración de la naturaleza como insumo productivo y la propagación del ecocidio reclaman instaurar otro tipo de metabolismo social donde la simbiosis con los ecosistemas se reconozca como fuente de la vida. Asimismo, la perversión de la democracia como potestad de las elites en detrimento del poder popular invoca un cambio político profundo para generalizar la democracia como un genuino principio de las relaciones humanas y de las instituciones basadas en la soberanía popular. En el mismo sentido, la homogeneización de la cultura neoliberal tiene que ser confrontada con la interacción entre las diversas culturas y la pluriversidad en un horizonte de emancipación social.

\section{Referencias}

Amin, Samir (2009), «¿Salir de la crisis del capitalismo o salir del capitalismo en crisis??, El viejo topo (261).

Arrizabalo, Xavier (febrero de 2012), «El imperialismo, los límites del capitalismo y la crisis actual como encrucijada histórica», XIII Jornadas de Economía Crítica. Los costes de la crisis y alternativas en construcción, pp. 705-736. Badiou, Alain et al. (2013), El sintoma griego. Posdemocracia, guerra monetaria y resistencia en la Europa de hoy, Madrid, Errata Naturae. 
Bartra, Armando (2006), El capital en su laberinto. De la renta de la tierra a la renta de la vida, México, Universidad Autónoma de la Ciudad de México/Ítaca. (2013), «Crisis civilizatoria», en Raúl Ornelas (coord.), Crisis civilizatoria y superación del capitalismo. México, Universidad Nacional Autónoma de México.

Damián, Víctor (2015), «La producción de consumidores y el estancamiento económico», Revista de Ciencias Sociales (28).

Dussel, Enrique (2016), 14 tesis de ética. Hacia la esencia del pensamiento crítico, México, Trotta.

Estermann, Josef (2012), «Crisis civilizatoria y vivir bien», Polis (33).

Fondo Monetario Internacional (FMI) (2009), Perspectivas de la economía mundial, Washington, FMI.

Gutiérrez, Eduardo (2010), «Prospectiva de la crisis: la salida diseñada por las elites occidentales», Viento Sur (112).

Harvey, David (2014), Diecisiete contradicciones y el fin del capitalismo, Quito, IAEN. Katz, Claudio (2011), «Las tres dimensiones de la crisis», Ciclos en la Historia, la Economía y la Sociedad, 19(38).

Klein, Naomi (2007), La doctrina del shock. El auge del capitalismo del desastre, Buenos Aires, Paidós.

Krugman, Paul (2012), ¿Acabad ya con esta crisis!, Barcelona, Crítica.

Lander, Edgardo (2011), «Los límites del planeta y la crisis civilizatoria», Revista Venezolana de Economía y Ciencias Sociales, 17(1), pp. 141-166.

Laval, Christian y Pierre Dardot (2013), La nueva razón del mundo. Ensayo sobre la sociedad neoliberal, Barcelona, Gedisa.

Löwy, Michael (2009), «Crisis ecológica, crisis capitalista, crisis civilizatoria: la alternativa ecosocialista», Razón y Revolución (29). 
Márquez, Humberto (2009), «Diez rostros de la crisis civilizatoria del sistema capitalista mundial», Problemas del desarrollo, 40(159), pp. 191-210. (2010), «La gran crisis del capitalismo neoliberal», Andamios, 7(13).

Márquez, Humberto y Raúl Delgado Wise (2011), «Una perspectiva del sur sobre capital global, migración forzada y desarrollo alternativo», Migración y Desarrollo, $9(16)$.

Marx, Karl ([1867] 2004), El capital. Crítica de la economía política, México, Siglo XXI.

Programa de las Naciones Unidas para el Desarrollo (PNUD) (2014), Informe sobre desarrollo humano 2014. Sostener el progreso humano: reducir vulnerabilidades y construir resiliencia, Nueva York, PNUD.

Rubio, Blanca (2011), «La nueva fase de la crisis alimentaria mundial», Mundo Siglo XXI, 6(24).

Sáenz, Roberto (2012), «Perspectivas del capitalismo a comienzos del siglo XXI», Socialismo o Barbarie (20).

Sen, Amartya (2009), "Capitalism Beyond the Crisis», The New York Review of Books, 56(5), in http://www.nybooks.com/articles/2009/03/26/ capitalism-beyond-the-crisis/

Stein, Ben (26 de noviembre de 2006), «In Class Warfare, Guess Which Class Is Winning», The New York Times, in http://www.nytimes.com/2006/11/26/ business/yourmoney/26every.html?r=0

Stiglitz, Joseph (2010), «Regulación y fallas», Revista de Economía Institucional, $12(23)$.

Ugarteche, Oscar (2012), «México: tan lejos de Dios, tan cerca de la crisis». Mecanismos de contagio de la crisis en Norteamérica», Nueva Sociedad (237), en http://www.obela.org/system/files/La\%20crisis\%20de\%20norteamerica.pdf Varoufakis, Yanis (2012), El minotauro global, México, Crítica. 